\title{
Uji Kinerja Turbin Arus Laut Twin Hull (Lambung Ganda) - 10 kW di Jembatan Suramadu
}

\author{
Afian Kasharjanto*1, Daif Rahuna ${ }^{1}$ \\ ${ }^{1}$ Balai Teknologi Hidrodinamika - Badan Pengkajian dan Penerapan Teknologi \\ Jl. Jalan Hidrodinamika - BPPT Kampus ITS, Sukolilo - Surabaya \\ *Email: afian.kasharjanto@gmail.com
}

DOI: 10.25042/jpe.052017.04

\begin{abstract}
Abstrak
Melalui Program Pengembangan Teknologi Industri (PPTI) - Ristekdikti tahun 2016 telah di lakukan uji fungsi Turbin Arus Laut Twin Turbine -10 Kilowatt selama 1 (satu) bulan sejak 28 Nopember sampai dengan 30 Desember 2016. Turbin yang di gunakan adalah turbin yang pernah di uji pada tahun 2015 dilokasi yang sama yaitu di bawah Jembatan Suramadu - Pile 56. Secara mekanik terjadi perbaikan pada rasio sistem transmisi bevel gear dimana pada awalnya rasio di buat $1: 22,5$. Pada uji coba yang sekarang, rasio bevel di turunkan menjadi $1: 12,0$. Perubahan di lakukan karena putaran generator melebihi putaran maksimum yang di ijinkan akibat rasio putaran yang terlalu besar (sehingga terjadi istilah nge-drip pada inverter). Ukuran turbin sebetulnya di desain untuk operasional pada lingkungan dengan kecepatan arus laut sekitar 2 m/detik, tetapi pada lokasi di Jembatan Suramadu kecepatan arus laut maksimal (sesuai data pengukuran ADCP tim Kementerian Kelautan dan Perikanan tahun 2015) adalah sebesar 1,26 m/detik sehingga hasil putaran turbin tidak terlalu optimal. Meskipun demikian, berdasarkan data pengukuran, energi yang di hasilkan cukup untuk dimanfaatkan sebagai sumber penerangan di sekitar Jembatan. Selama periode uji coba, cutt-in speed terjadi pada kecepatan arus 0,6 m/detik dan menghasilkan daya minimal pada masing-masing generator sebesar 480 Watt dan kecepatan arus maksimal terjadi pada $1,10 \mathrm{~m} /$ detik, menghasilkan daya maksimal 2,230 watt. Beban lampu di distribusikan bukan hanya di dalam turbin tetapi juga di tempelkan pada tiang Pile-56 sebagai uji coba untuk penerangan di sepanjang jalan raya pada Pile-56 Jembatan Suramadu.
\end{abstract}

\begin{abstract}
Performance Test of a $10 \mathrm{~kW}$ Twin Hull Current Turbine at Suramadu Bridge. Through an Industrial Technology Program (PPTI) - Ministry of Research,Technology and Higher Education 2016, we have conducted a functional Twin Turbine Testing of 10 Kilowatt Power for 30 days on site (started from 28 Nopember 2016 until 30 Desember 2016). The turbine is still the same as the one that has been used and tested in 2015 but some modification was given to, such as transmission ration modification (originally $1: 22.5$ become $1: 12$ ), additional turbine wall (to keep from wind and rain). Because of that, the turbine performance become much-much better because the turbine rotation was not exceeded the maximum generator rotation. Actually, turbine is designed for current speed 2 meter/sec minimum to reach 10 Kilowatt power output. In fact, but the current speed was only $1.26 \mathrm{~m} / \mathrm{sec}$ average (based on data taken from ADCP (Acoustic Doppler Current Profiler) surveyed by researchers from Ministry of maritime and fisheries in 2015 so targeted power output (10 kilowatt) could not be reached. Nevertheless the energy output is pretty enough to produce energy used for sourch of light along the way on the bridge. Cutt-in speed was $0.6 \mathrm{~m} / \mathrm{sec}$ to make rotor start rotating. Power output was only 480 watt in each generator in $1.1 \mathrm{~m} / \mathrm{sec}$ current speed. The lights was distributed not only inside turbine but also embedded on a pile as trial for lighting along the main road of Suramadu bridge especially arround Pile-56.
\end{abstract}

Kata-kunci: Cutt-in speed, jembatan suramadu, rasio transmisi mekanik, uji fungsi turbin

\section{Pendahuluan}

Laut Indonesia menyediakan sumber energi baru dan terbarukan yang berkelanjutan dan melimpah. Sumber energi terbarukan dari laut terdiri dari : energi arus laut, energi pasang surut, energi perbedaan temperatur air laut (OTEC), dan energi ombak/gelombang. Dari sumber-sumber tersebut yang dalam sepuluh tahun ini sedang diteliti lebih intensif adalah energi arus laut.

Pemerintah (kantor kementerian ESDM) telah merencanakan program pengembangan sumber energi dari laut. ESDM telah mengusulkan roadmap UU No 30 tahun 2007 tentang Energi, PP 79 tahun 2014 tentang KEN, RPJMN 2015-2019 serta RUPTL dan telah 
disusun RUEN (Rencana Umum Energi Nasional) sesuai Perpres No. 22 Tahun 2017 yang bertujuan untuk mewujudkan kemandirian energi serta mewujudkan ketahanan energi Nasional [1].

Untuk merealisasikan tujuan tersebut, ada 2 (dua) strategi yang akan di laksanakan, yaitu:

- Pemasangan Turbin skala besar untuk memenuhi kebutuhan energi secara umum dalam rangka bauran energy, serta

- Skala kecil untuk memperluas akses ke remote area, wilayah perbatasan dan pulau pulau kecil terluar

Energi arus laut mempunyai prospek cerah karena dapat dihitung di atas kertas dengan pasti potensi daya listriknya. Hal ini karena arus laut terutama disebabkan oleh interaksi gaya tarik menarik antara bumi, bulan, dan matahari. Jadi faktor cuaca sama sekali tidak berpengaruh pada arus laut. Hampir 98\% dapat di prediksi di atas kertas potensi arus laut yang akan terjadi.

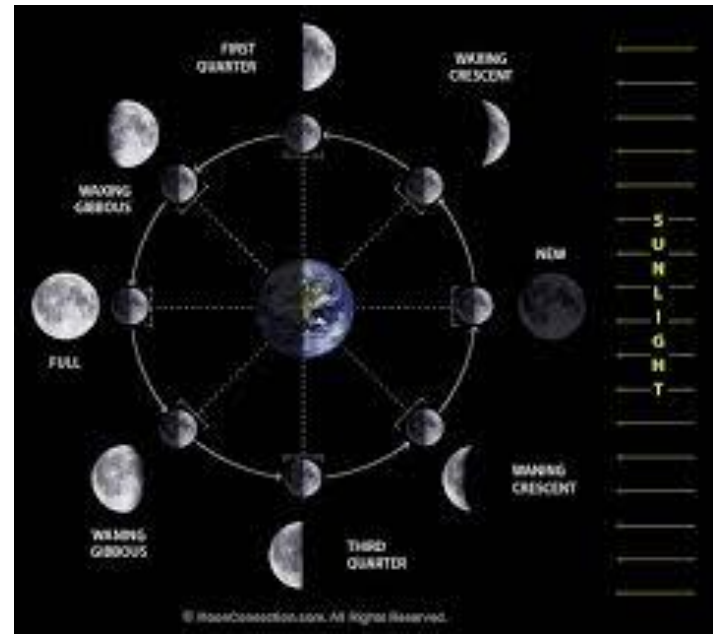

Gambar 1. Fase posisi bulan mengelilingi bumi

Dari gambar diatas diketahui bahwa saat bulan, bumi dan matahari berada di satu garis lurus (sejajar) maka akan terjadi bulan penuh, sedangkan disaat bumi, bulan dan matahari tegak lurus akan terjadi bulan bulan baru. Pada saat itulah terjadi gaya gravitasi bulan paling besar dan terjadinya momen inersia akibat putaran bumi sehingga terjadi pasang semi (spring tide). Sedangkan pada saat posisi bulan tegak lurus dengan bumi maka terjadi bulan setengah (half moon), dan disaat itu akan terjadi pasang perbani (neap tide).
Bandingkan dengan energi angin yang tergantung pada cuaca, energi matahari tergantung pada mendung atau hujan, energi arus laut hanya tergantung pada keberadaan dan posisi bumi terhadap bulan dan matahari dimana hal tersebut terjadi secara berulang dan dapat di perkirakan.

Dalam rangka mendukung Kebijakan Energi Nasional yang ditetapkan melalui PP No. 79 Tahun 2014, dimana kontribusi energi baru dan terbarukan (EBT) terus ditingkatkan dari target sebelumnya sebesar $17 \%$ menjadi $23 \%$ pada tahun 2025, Energi Baru dan Terbarukan (EBT) terus dikembangkan dan dioptimalkan, dengan mengubah pola fikir (mind-set) bahwa EBT bukan sekedar sebagai energi altenatif dari Bahan Bakar fosil, tetapi harus menjadi penyangga pasokan energi Nasional (Perpres no. 5/2006 tentang kebijakan energi Nasional), maka BPPT melalui pengalaman dalam desain, uji laboratorium, uji prototipe dan telah mendapatkan sertifikat PATEN dalam desain turbin arus, siap untuk berkontribusi dalam proses industrialisasi Turbin arus laut.

Pertimbangan Kapasitas $10 \mathrm{~kW}$ dianggap ideal untuk pemanfaatan Turbin di Indonesia karena sebagai Negara yang terdiri banyak Pulau, Indonesia tidak memerlukan Turbin dengan kapasitas yang besar tetapi cukup Turbin dengan kapasitas skala kecil/menengah tetapi dalam jumlah banyak (small many) karena [2]:

1. Sebaran penduduk di pulau-pulau kecil yang cenderung tidak merata.

2. Sifat kebanyakan kecepatan arus laut di selat-selat maksimum hanya $2 \mathrm{~m} / \mathrm{s}$ atau kurang.

3. Infrastruktur daerah untuk perakitan PLTAL masih minim.

4. Fasilitas peralatan pendukung di Daerah (crane, Kapal penarik, dermaga dll) sangat minim atau tidak ada.

5. Industri pendukung kebanyakan terpusat ada di Jawa

6. Standarisasi dan regulasi produk masih belum ada

Berdasarkan hasil kajian aspek-aspek di atas maka BPPT mem-fokuskan diri dalam hal kajian Turbin skala kecil kapasitas $10 \mathrm{~kW}$ dengan memperhatikan aspek kemudahan transportasi, 
perakitan, instalasi, pemasangan, dan pemeliharaan.

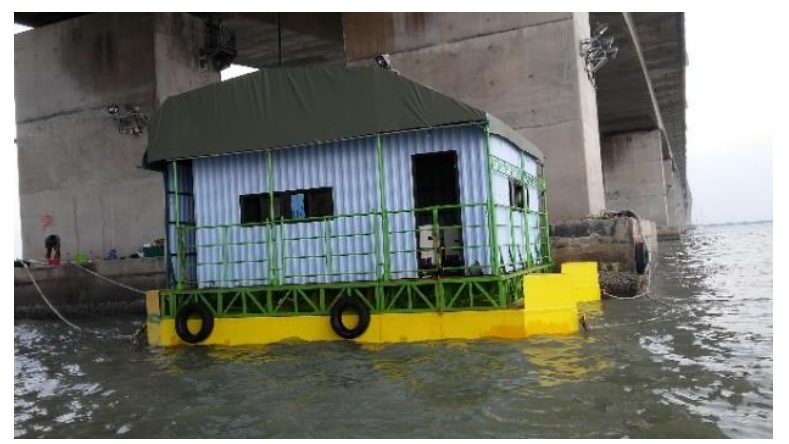

Gambar 2. Saat pengujian Turbin $10 \mathrm{~kW}$ di Suramadu

\section{Pengujian model turbin arus laut twin hull $-10 \mathrm{Kw}$}

Turbin arus laut Twin Hull adalah Turbin milik Balitbang Kementerian Kelautan dan Perikanan. Proses desain, manufacturing dan di uji oleh para perekayasa dari PTRIM - BPPT.

Dari desain awal telah ditentukan bahwa turbin menggunakan 3 (tiga) buah generator dengan masing-masing kapasitas sebesar 3,5 Kw. Diameter turbin $1,850 \mathrm{~m}$, panjang (span) bilah adalah ( $\mathrm{C}_{\text {Length }}$ ) 2,183 $\mathrm{m}$ dan lebar chord ( $\left.\mathrm{C}_{\text {Breadth }}\right)$ 1,86 m.Rasio gear box sebesar $1: 12$ di gunakan untuk meneruskan gaya putaran dari rotor menuju generator. Besarnya daya listrik yang di hasilkan bergantung pada densitas air laut, penampang aliran, dan kecepatan alirannya [3].

Kapasitas $10 \mathrm{~kW}$ adalah kapasitas yang dianggap ideal untuk di manfaatkan di Indonesia karena kondisi perairan di Indonesia lebih cocok untuk pemasangan turbin skala kecil/menengah [4], karena :

1. Sebaran penduduk di pulau-pulau kecil cenderung tidak merata (dalam jumlah sedikit

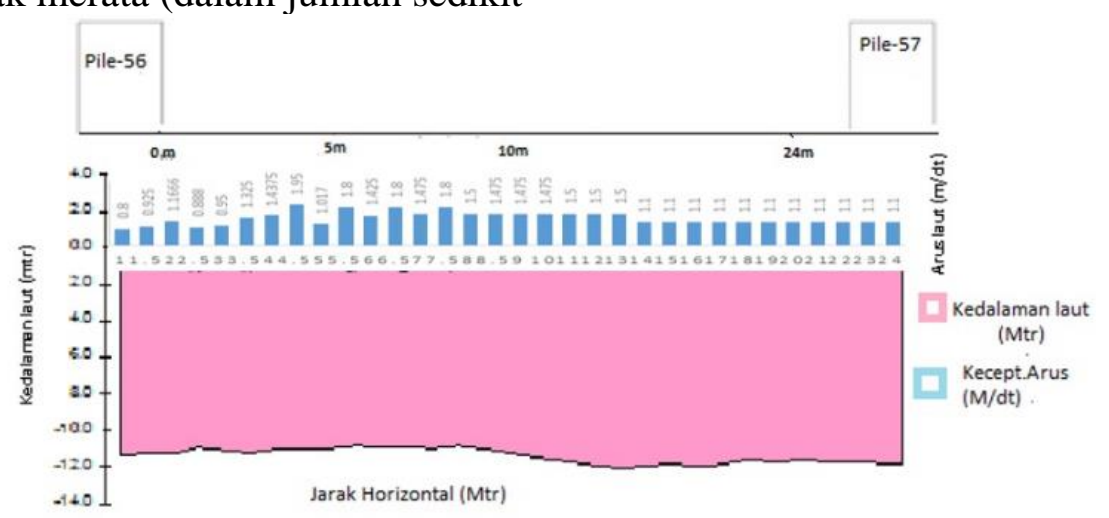

Gambar 4. Data kedalaman dan kecepatan arus laut di sekitar Pile-56 suramadu tetapi meyebar)

2. Sifat kebanyakan kecepatan arus laut ratarata $2 \mathrm{~m} / \mathrm{s}$ (meskipun ada beberapa yang di atas kecepatan rata-rata)

3. Infrastruktur Daerah untuk perakitan PLTAL minim sehingga sulit untuk pemasangan turbin skala besar.

4. Fasilitas alat pendukung (crane, barge, berth, dan lain-lain) sangat minim.

5. Industri pendukung di Daerah tidak ada/sedikit.

6. Standarisasi dan regulasi Energi arus laut yang belum ada.

7. Sertifikasi untu alat, personil, maupun prosedur belum ada.

Secara umum skema kerja turbin adalah sebagai berikut :

\section{DIAGRAM PUTARAN TWIN TURBINE $10 \mathrm{KW}$}

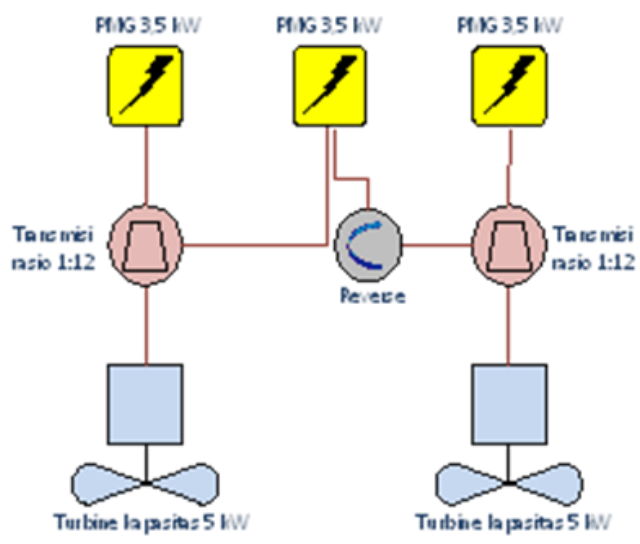

Gambar 3. Skema kerja turbin

Data kecepatan arus dan kedalaman perairan pada lokasi pengujian seperti data di bawah ini [5]: 


\section{Data pengujian turbin}

Gambar desain sistem kerja Turbin dapat di lihat seperti gambar di bawah ini :

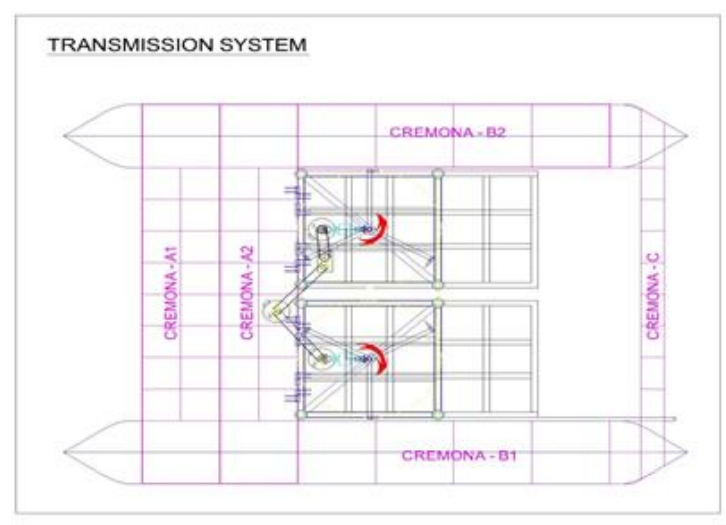

Gambar 5. Desain Turbin

Masing-masing rotor dihubungkan ke generator melalui system transmisi gear box. Putaran rotor ke 1 di hubungkan ke Generator ke 1 , putaran rotor ke 2 di hubungkan ke Generator ke 2. Kemudian masing-masing generator ke1 dan ke 2 di hubungkan ke generator ke 3 menggunakan mekanisme sambungan Pulley sehingga ketiga generator dapat berputar bersamaan.

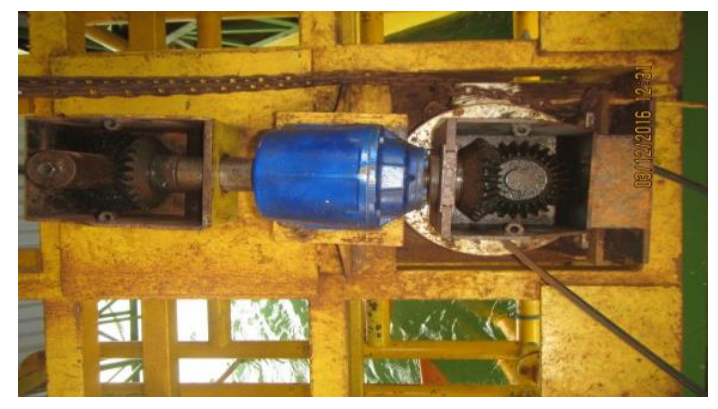

Gambar 6. Sistem hubungan transmisi antara generator dan poros rotor (untuk satu generator)

Selanjutnya masing-masing inverter di hubungkan ke masing-masing Generator yang selanjutnya di salurkan ke beban / lampu.

Lokasi uji turbin berada di bawah Jembatan Suramadu pile 56, pada posisi LS $7^{\circ} 09^{\prime} 50.4^{\prime \prime}$ LS $7^{\circ} 10^{\prime}$ 03.48' dan LE $112^{\circ} 47^{\prime} 03.84^{\prime \prime}$ - LE $112^{\circ} 46^{\prime}$ 50.84", dengan kedalaman perairan antara $10 \mathrm{~m}$ sampai dengan $12 \mathrm{~m}$ [8]

Hasil listrik dari putaran rotor akan dimasukkan ke dalam Accu (12 Volt, $220 \mathrm{Ah}$, deep cycle, accu kering) sebagai penyimpan (power bank) terlebih dahulu sebelum listrik di salurkan ke beban lampu.
Selama proses uji coba, setiap hari dilakukan pengukuran kecepatan arus laut seperti data di bawah ini (mulai 28 Nopember sampai dengan 30 Desember 2016) seperti data di bawah ini [8]:

Tabel 1. Hubungan fase lunar dengan besaran kecepatan arus [8]

\begin{tabular}{|c|c|c|c|c|c|}
\hline \multirow{2}{*}{ Tgl. } & \multirow{2}{*}{$\begin{array}{c}\text { Fase } \\
\text { Lunar }\end{array}$} & \multicolumn{2}{|c|}{ V $_{\text {Arus }}(\mathbf{m} / \mathbf{s})$} & \multirow[b]{2}{*}{ Durasi } & \multirow{2}{*}{ Freq. } \\
\hline & & Min & Max & & \\
\hline $\begin{array}{c}28 \\
\text { Nov }\end{array}$ & & 0,6 & 1,0 & 9,5 & 2 \\
\hline $\begin{array}{c}29 \\
\text { Nov }\end{array}$ & & 0,6 & 1,0 & 10,5 & 2 \\
\hline $\begin{array}{c}30 \\
\text { Nov }\end{array}$ & & 0,6 & 1,1 & 10,5 & 2 \\
\hline 1 Des & & 0,6 & 1,0 & 9,5 & 2 \\
\hline 2 Des & & 0,6 & 0,9 & 7,5 & 2 \\
\hline 3 Des & & 0,6 & 0,9 & 6,5 & 2 \\
\hline 4 Des & & 0,6 & 0,8 & 5,5 & 2 \\
\hline 5 Des & & 0,6 & 0,7 & 6 & 2 \\
\hline 6 Des & & 0,6 & 0,7 & 5 & 2 \\
\hline 7 Des & & 0,6 & 0,7 & 4 & 2 \\
\hline 8 Des & & 0,6 & 0,7 & 5,5 & 2 \\
\hline 9 Des & & 0,6 & 0,8 & 4 & 2 \\
\hline $\begin{array}{c}10 \\
\text { Des }\end{array}$ & & 0,6 & 0,8 & 4,5 & 2 \\
\hline $\begin{array}{c}11 \\
\text { Des }\end{array}$ & & 0,6 & 0,9 & 4 & 2 \\
\hline
\end{tabular}




\begin{tabular}{|c|c|c|c|c|}
\hline $\begin{array}{c}12 \\
\text { Des }\end{array}$ & 0,6 & 1,0 & 7,5 & 2 \\
\hline $\begin{array}{c}13 \\
\text { Des }\end{array}$ & 0,6 & 1,0 & 8,5 & 2 \\
\hline $\begin{array}{c}14 \\
\text { Des }\end{array}$ & 0,6 & 1,1 & 8,5 & 2 \\
\hline $\begin{array}{c}15 \\
\text { Des }\end{array}$ & 0,6 & 0,9 & 10 & 2 \\
\hline $\begin{array}{c}16 \\
\text { Des }\end{array}$ & 0,6 & 0,8 & 10,5 & 2 \\
\hline $\begin{array}{c}17 \\
\text { Des }\end{array}$ & 0,6 & 0,7 & 9,5 & 2 \\
\hline $\begin{array}{c}18 \\
\text { Des }\end{array}$ & 0,6 & 0,8 & 8,5 & 2 \\
\hline $\begin{array}{c}19 \\
\text { Des }\end{array}$ & 0,6 & 0,7 & 6 & 2 \\
\hline $\begin{array}{c}20 \\
\text { Des }\end{array}$ & 0,6 & 0,7 & 5 & 2 \\
\hline $\begin{array}{c}21 \\
\text { Des }\end{array}$ & 0,6 & 0,7 & 4 & 2 \\
\hline $\begin{array}{c}22 \\
\text { Des }\end{array}$ & 0,6 & 0,8 & 4,5 & 2 \\
\hline $\begin{array}{c}23 \\
\text { Des }\end{array}$ & 0,6 & 0,7 & 4 & 2 \\
\hline $\begin{array}{c}24 \\
\text { Des }\end{array}$ & 0,6 & 0,7 & 4,5 & 2 \\
\hline $\begin{array}{c}25 \\
\text { Des }\end{array}$ & 0,6 & 0,8 & 6,5 & 2 \\
\hline $\begin{array}{c}26 \\
\text { Des }\end{array}$ & 0,6 & 0,9 & 9,5 & 2 \\
\hline $\begin{array}{c}27 \\
\text { Des }\end{array}$ & 0,6 & 1,0 & 9,5 & 2 \\
\hline $\begin{array}{c}28 \\
\text { Des }\end{array}$ & 0,6 & 1,0 & 10 & 2 \\
\hline
\end{tabular}

\begin{tabular}{|c|c|c|c|c|}
\hline $\begin{array}{c}29 \\
\text { Des }\end{array}$ & 0,6 & 1,0 & 9,5 & 2 \\
\hline $\begin{array}{c}30 \\
\text { Des }\end{array}$ & 0,6 & 0,9 & 9 & 2 \\
\hline
\end{tabular}

Secara grafis, perbandingan prosentase besaran masing-masing kecepatan arus laut selama periode satu bulan adalah :

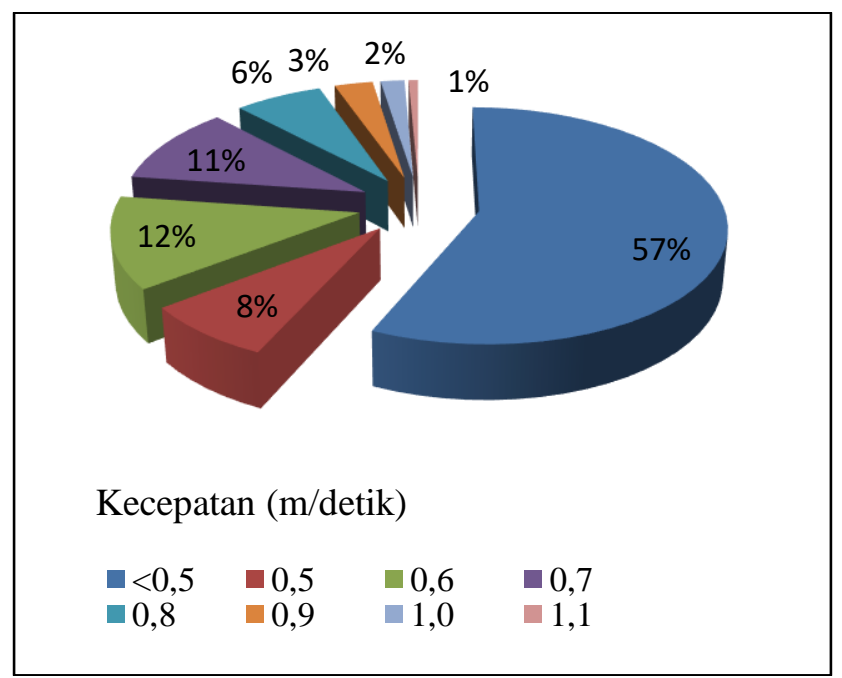

Gambar 7. Sebaran kecepatan arus (m/detik) selama 30 hari uji coba :

\section{Pembahasan}

Berdasarkan rumus [6]:

$$
P(\text { Watt })=\frac{1}{2} \rho A V^{3} \eta
$$

Dimana :

$P$ : Daya listrik (Watt)

$\rho:$ Densitas air laut $\left(\mathrm{Kg} / \mathrm{m}^{3}\right)$

$A$ : Luasan penampang melintang rotor turbin $\left(\mathrm{m}^{2}\right)$

$V:$ Kecepatan arus laut $(\mathrm{m} / \mathrm{det})$

$\eta$ : Efisiensi

Maka kita dapat mengetahui besaran daya operasional turbin dari hasil pengukuran kecepatan arus, putaran turbin dan putaran generator. 
Tabel 2. Pengukuran kecepatan arus, putaran rotor dan generator

\begin{tabular}{cccccc}
\hline $\begin{array}{c}\text { Kec. arus, } \boldsymbol{v} \\
(\boldsymbol{m} / \mathbf{s})\end{array}$ & \multicolumn{2}{c}{$\begin{array}{c}\text { Putaran turbin, } \\
\boldsymbol{n}_{\boldsymbol{t}}(\boldsymbol{r p m})\end{array}$} & \multicolumn{2}{c}{$\begin{array}{c}\text { Putaran } \\
\text { generator, } \boldsymbol{n}_{\text {pmg }} \\
(\boldsymbol{r p m})\end{array}$} \\
\hline Vin & Vout & $\mathbf{1}$ & $\mathbf{2}$ & $\mathbf{1}$ & $\mathbf{2}$ \\
\hline 0,6 & 0,4 & 7,4 & 7,4 & 88,8 & 88,8 \\
0,7 & 0,4 & 9,3 & 9,3 & 111,6 & 111,6 \\
0,8 & 0,5 & 10,4 & 10,4 & 124,8 & 124,8 \\
0,9 & 0,6 & 11,2 & 11,2 & 134,4 & 134,4 \\
1,0 & 0,6 & 12,4 & 12,4 & 148,8 & 148,8 \\
\hline
\end{tabular}

Keterangan :

$\mathrm{V}_{\text {in }}$ : Kecepatan air laut sebelum melewati rotor turbin.

$\mathrm{V}_{\text {out }}$ : Kecepatan air laut setelah melewati rotor turbin.

Perbandingan daya listrik antara daya teoritis dari formula dengan realitas pada generator untuk mengetahui effisiensi listrik sebagai fungsi kecepatan air dapat dilihat pada grafik di bawah ini [8]:

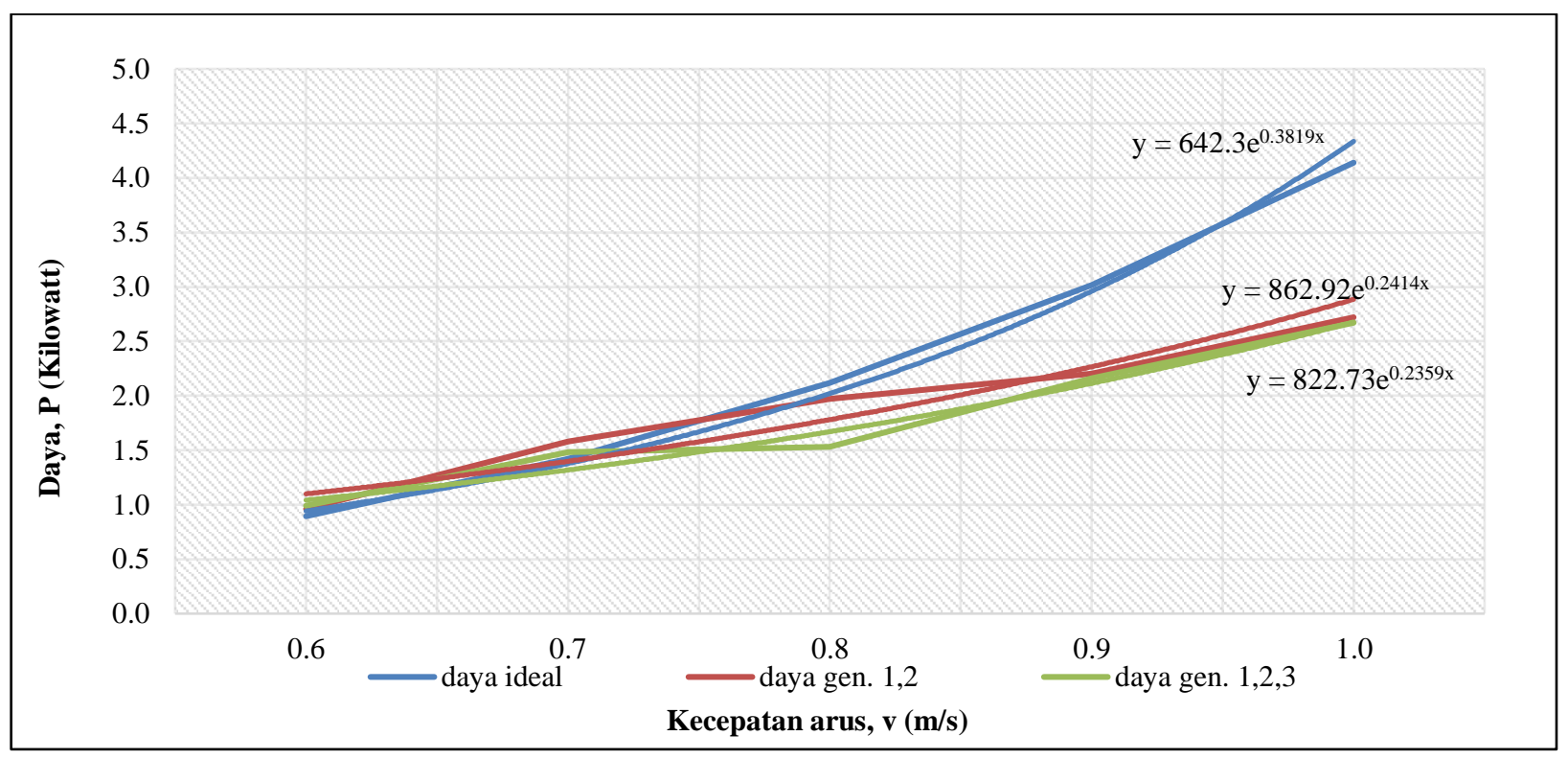

Gambar 8. Perbandingan besaran daya ideal dengan daya yang di hasilkan oleh generator 1, 2 dan 3

Pada Gambar 8 menunjukkan perbandingan perhitungan daya teoritis dengan daya total yang di hasilkan oleh ke tiga generator dengan asumsi effisiensi-nya satu.
Kemudian dari inverter (sebagai fungsi kecepatan arus laut) dapat di lihat besaran daya sebagai berikut :

Tabel 3. Perbandingan luaran daya teoritis dengan daya dari Generator

\begin{tabular}{ccccc}
\hline \multirow{2}{*}{ No } & $\begin{array}{c}\text { Kecepatan arus laut } \\
(\mathbf{m} / \text { detik) }\end{array}$ & Teoritis & $\begin{array}{c}\text { Total daya per generator } \\
\text { (formasi dua generator) }\end{array}$ & $\begin{array}{c}\text { Total daya per generator } \\
\text { (formasi tiga generator) }\end{array}$ \\
\cline { 2 - 5 } & 0,6 & 894,14 & 480 & 330 \\
1 & 0,7 & 1429,85 & 790 & 495 \\
2 & 0,8 & 2119,43 & 985 & 510 \\
3 & 0,9 & 3017,7 & 1100 & 720 \\
4 & 1,0 & 4139,51 & 1360 & 890 \\
5 & & &
\end{tabular}

Terjadi penurunan besaran daya listrik ketika ke tiga generator di hubungkan semuanya karena terjadi slip (penurunan putaran) pada generator akibat system dapat di hitung besaran effisiensi turbin adalah sebesar 35,5\%.
Pada saat ketiga generator di fungsikan semua, karena kalau system hubungan antara generator satu dan dua langsung menggunakan poros penghubung ke poros rotor turbin, tetapi dari generator satu dan dua menuju generator tiga 
masih dihubungkan dengan van belt (mudah terjadi slip/friction antara poros dengan van belt sehingga mengurangi kecepatan putaran poros turbin. Akibatnya efisiensi turbin hanya sebesar $35,5 \%$ yang artinya dengan daya generator terpasang 10.000 Watt, hanya 35.500 Watt daya listrik yang dapat di manfaat akibat kecepatan arus laut yang rendah di kawasan Suramadu.

\section{Kesimpulan}

- Effisiensi maksimum terjadi pada saat 2 (dua) generator dimana masing -masing generator di hubungkan langsung pada masing-masing rotor, yaitu 37\%. Sedangkan pada saat generator ke-3 di gabung pada 2 (dua) generator sebelumnya, efisiensi ternyata turun menjadi $19,8 \%$. Hal ini terjadi karena untuk menghubungkan Generator ke1 dan ke-2 menuju generator ke-3 (ketiga) masih menggunakan mekanisme sambungan belt yang menyebabkan tambahan gaya gesek (friction/slip) ketika poros berputar sehingga dapat menurunkan efisiensi sistem.

- Secara prinsip berdasarkan hasil uji coba, listrik telah berhasil menyala baik dengan beban lampu yang di pasang pada turbin maupun di luar turbin (sekitar tiang/pile jembatan). Jumlah total beban lampu 42 buah x 25 watt serta kompor listrik.

- Untuk mengetahui daya tahan peralatan kelistrikan dan mekanik terhadap karat karena air laut maupun angin selama beroperasi di laut, tahap berikutnya perlu dilanjutkan dengan melakukan uji ketahanan (indurance test) dalam jangka waktu yang agak lama (sekitar 6 bulan operasional di laut)

\section{Ucapan Terimakasih}

Disampaikan terima kasih kepada :

- Mitra dari Balitbang KP-Kementerian Kelautan dan Perikanan atas dukungan dan kerjasama dalam penelitian dan uji coba Turbin di Suramadu.

- Kementerian Ristekdikti dalam dukungan pembiayaan melalui program PPTI tahun anggaran 2016.

\section{Referensi}

[1] Berita ESDM, "Enegi baru dan terbarukan - Wilayah Perairan Indonesia Simpan Potensi Energy Listrik dari Arus Laut, www3.esdm.go.id/berita/energy-baru-danterbarukan/323-energi-baru-d, Rabu 27 april 2011.

[2] Dirjen EBTKE-ESDM, Forum Gorup Discussion, Rapat penyusunan road map pembangunan di bidang energy laut, Bogor, 16 Juni 2017.

[3] Erwandi, Afian.K, Laporan DIPA KKP, Pengujian Turbin Arus Laut Twin Hull Balitbang KKP di Jembatan Suramadu, 2015.

[4] Afian Kasharjanto, Proposal PPTI, Pemasangan dan uji kinerja pembangkit listrik arus laut kapasitas 10 Kilowatt di Depo Pertamina, Tanjungwangi, Banyuwangi, 2016.

[5] Akhmad Syafi'ul "Hasil surveyarus laut tim BTHBPPT di Suramadu", Laporan survey di Suramadu, DIPA kegiatan pengembangan energi arus laut, 2015.

[6] Software moonphase.exe, Free download, https://moonphase.en. softonic. com/.

[7] Erwandi, "Sumber energi arus laut dari Selat Larantuka, Uji coba prototype pembangkit listrik tenaga arus laut", https://pltal.wordpress.com,BPPT, posted on September 15, 2010.

[8] S.E. Ben Elghali,, Benbouzid, and J.F. Charpentier, "Modelling and control of a marine current Turbinedriven doubly fed induction generator, IEEExplore.ieee.org/document/5383257/IET Renewable power generation Volume 4, Issue 1, Januari 2010.

[9] Stephen P. Radzevich, "Dudley's hand book of practical gear design and manufacture", 2012. 